\section{CLARA \\ SCHUMANN E \\ TERESA \\ CARREÑO}

RevistaMúsica | vol. 19, n.2 |

pp. 123-131 | jul. 2019

\section{Nilcéia Baroncelli}

compositoras.mulheres@gmail.com | POLYMNIA - Grupo de Estudo de Mulheres na Música

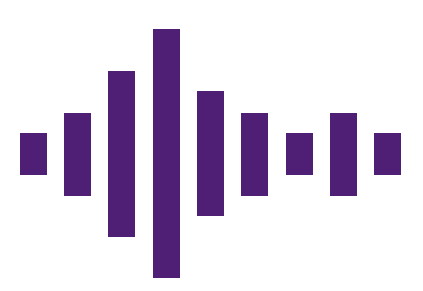

Recebido em: 18/05/2019

Aprovado em: 15/06/2019

\section{RESUMO}

O presente artigo apresenta duas compositoras e virtuosas do piano nascidas no século XIX, que compartilham, entre outras

características, a de terem sido provedoras de suas famílias numa época em que as mulheres tinham acesso restrito à atuação profissional principalmente no campo da música erudita. O objetivo é comparar as trajetórias pessoais e profissionais da alemã Clara Schumann e da venezuelana

Teresa Carreño, discutindo o impacto destes modelos na história das mulheres na música.

\section{PALAVRAS-CHAVE:}

Clara Schumann. Teresa Carreño. Mulheres compositoras. Piano.

\section{ABSTRACT}

The present article presents two women composers and piano virtuoses born in the 19th century, who share, among other characteristics, that of having been providers of their families at a time when women had restricted access to professional performance - especially in the field of classical music. The aim is to compare the personal and professional trajectories of German Clara Schumann and Venezuelan Teresa Carreño, discussing the impact of these models on the history of women in music.

\section{KEYWORDS:}

Clara Schumann. Teresa Carreño. Women composers. Piano. 


\title{
CLARA SCHUMANN E TERESA CARREÑO
}

\author{
Nilcéia Baroncelli \\ compositoras.mulheres@gmail.com | POLYMNIA - Grupo de \\ Estudo de Mulheres na Música
}

\section{Introdução}

Entre o nascimento de Clara Schumann (1819-1896), e o falecimento de Teresa Carreño (1853-1917) decorreram noventa e oito anos. Nasceram muito longe uma da outra - Clara em Leipzig, na Alemanha, e Teresa em Caracas, capital da Venezuela. Também a idade é distante: Clara nasceu em 1819 e Teresa em 1853, um ano depois do nascimento do oitavo filho de Clara. Depois que Clara faleceu, em 1896, Teresa ainda viveu vinte e um anos: até 1917.

Não há notícia de um encontro entre elas, nem se conhece alguma comparação em suas carreiras de intérpretes ou de compositoras. Mas, neste momento em que vivemos, o mais interessante é mostrar a figura de cada uma como provedora de sua família.

Suas vidas apresentam muitas simetrias, que às vezes seguem o mesmo curso, às vezes se opõem radicalmente. Ambas foram crianças prodígio, apresentadas ao público muito cedo, e granjeando imediatamente muito sucesso; ambas foram orientadas inicialmente por seus respectivos pais, e depois se desprenderam rumo a carreiras que (e aqui está a primeira oposição) foram muito regulares, o que é o caso de Clara Schumann, ou muito irregulares, como é o caso de Teresa Carreño. Irregular, mas, apesar de tudo, nunca interrompida. Clara foi sempre pianista; Teresa se dedicou, no começo da longa carreira, também à ópera, como cantora e como principal nome de uma companhia lírica.

\section{Clara Schumann (1819-1896)}

Clara começou a carreira solo, para a qual seu pai a preparou, em 1830, aos onze anos. Teve um grande sucesso e ele começou a programar viagens, começando na Alemanha até chegar a Paris, capital cultural do mundo na primeira metade do século XIX. Clara tocava autores da época e também sua obra Variações sobre um tema original; no ano seguinte suas Quatro Polonaises op. 1 foram editadas em Leipzig. Aos quinze anos já tinha nome e reputação como pianista, e nem sempre aceitava o repertório que seu pai programava. 
Em 1830, Robert Schumann começou a estudar música com Friedrich Wieck, pai de Clara. Durante uma turnê, que durou cerca de um ano, Schumann, que já estudava com Wieck, se sentiu abandonado e reclamou da ausência dela, mas, nesse ínterim, estudou Composição e Contraponto. Foi nesse período que escreveu a peça Papillons op. 2, que consta de repertórios e gravações até hoje. Quando Clara e o pai retornaram dessa viagem de sucesso, Friedrich se encanta com a peça, e começa a introduzir outras obras do jovem compositor no repertório da filha.

Com o passar do tempo e a proximidade que o futuro casal demonstrava, Friedrich Wieck percebeu o afeto e atração que se desenvolvia entre eles. Apesar de gostar muito do rapaz, o pai não queria que Clara se casasse com ele, pois havia notado as oscilações de seu temperamento. Entrementes, Robert passou a escrever sobre música, pois havia perdido a esperança de uma carreira de concertista, devido ao uso de um mecanismo que afetou os movimentos de sua mão direita. Fundou, em 1834, um periódico no qual expressava suas ideias musicais e para o qual criou personagens fictícios, que incorporavam sua diversidade de pensamento.

Em 1836, quando o pai de Clara percebeu que eles estavam se aproximando muito, mandou-a para Dresden, mas o namorado foi visitá-la e, por cautela, Wieck programou uma turnê que ela deveria fazer sozinha. Nessa ocasião, ela foi contemplada não só com muitos aplausos como também teve reconhecimento como compositora. Além disso, foi elogiada pelo compositor Spontini e teve obras editadas, inclusive seu Concerto para piano op. 7 , recebendo remuneração pelas publicações. E ganhou experiência em programar tudo o que é necessário para um concerto: local e data, locação da sala, encontrar carregadores de piano, afinadores, impressão dos ingressos, envio dos de cortesia, e às vezes até vendê-los.

Na véspera do $21^{\circ}$ aniversário de Clara, e depois de enfrentar um processo que visava impedir a união dos dois apaixonados, eles conseguiram se casar. Foi o início de um período de muita felicidade para ambos, do ponto de vista pessoal. E também o início do enorme sofrimento que os acompanhou, devido aos problemas de saúde que Robert apresentava desde antes, uma vez que sua instabilidade emocional fora percebida, e era a causa da tentativa de separação de ambos, promovida por Wieck.

No decorrer de doze anos de casamento, a partir de 1841, Clara teve oito filhos. Em 1843, um pouco por esforço dela, as peças pianísticas de Robert começam a ter sucesso. A primeira filha foi Marie, que nasceu em setembro de 1841; em seguida nasceram Elise (1843), Julie (1845), Emil (1846), Ludwig (1848), e Ferdinand (1849). No ano seguinte, o casal se mudou para Düsseldorf, na Baixa Renânia, onde nasceram 
Eugenie (1851) e Felix (1854). Nessa cidade, Robert escreveu a Sinfonia Renana op. 97, pensando no Rio Reno, e passou a reger o coro da cidade.

Percebendo sua própria instabilidade física e emocional, Schumann consultou um médico que aconselhou uma viagem terapêutica à Holanda. Ali, ela, sempre envolvida com problemas domésticos, e ocupando cada vez mais o papel de chefe de família, sente dramaticamente o efeito do descuido com a própria saúde: sofre um aborto. Voltando a Düsseldorf, Clara procura um espaço onde ambos possam se dedicar a seus afazeres em separado, e mudam para uma casa onde conseguia estudar enquanto ele compunha.

Mas também ela escreve música, e em 1853 produz seus opp. 20 a 23. Tudo melhora, e eles comemoram os 34 anos dela e os 13 de casamento com um novo piano que seu marido, que estava bem melhor, oferece a ela. É no mesmo mês de seu aniversário que o casal conhece Brahms; mas em seguida Robert se demite de sua função de regente, que havia assumido em substituição a Ferdinand Hiller. Em fevereiro de 1854 ele se atira ao Reno, depois de sucessivos incômodos auditivos e de alucinações, mas foi salvo por pescadores. Depois disso, ele piora e pede para ser internado, o que acontece em Endenich, subúrbio de Bonn. Em 1856, depois de uma internação em que piorava cada vez mais, Robert Schumann se foi.

Clara sobreviveu a Robert 40 anos, durante os quais acabou de criar os filhos, deu aulas, fez muitos recitais, leu as obras de Brahms e opinou sobre elas - sempre sendo aceita em seus conselhos. Editou as obras de Robert, mudou de cidade muitas vezes, e manteve sempre os amigos mais fiéis, como Joseph Joachim, violinista com o qual realizou, a partir do Festival do Baixo Reno, em Düsseldorf, mais de 230 recitais. No período desse Festival, Robert Schumann estivera bem de saúde e regeu o Concerto para violino e orquestra em ré maior op. 61, de Beethoven. Com outro excelente artista, o barítono Julius Stockhausen, Clara dividiu o palco um sem-número de vezes. Estrearam muitas peças de Schumann para canto. Stockhausen foi um dos primeiros intérpretes de lieder no século XIX.

\section{Teresa Carreño (1853-1917)}

Teresa Carreño nasceu em Caracas no dia 22 de dezembro de 1853, descendente de tradicional família venezuelana. Começou a estudar piano com o próprio pai e logo se desenvolveu tecnicamente, começando a compor aos nove anos. Em 1862, Teresa mudou com a família para Nova Iorque, onde passou a tocar com muito sucesso. Lá conheceu Louis Moreau Gottschalk, pianista e compositor reconhecido tanto na Europa quanto na 
América. Teresa publicou a primeira música em 1862, e em 1865 ou 1866, teve a música Corbeille des Fleurs editada em Paris, que esse intérprete sempre apresentava.

Em 1863, a convite do Presidente Abraham Lincoln, Teresa tocou na Casa Branca; e a família permaneceu nos Estados Unidos, onde o pai sustentava a família dando aulas de música. Teresa ocasionalmente se apresentava em Nova Iorque, Boston, Baltimore e outras cidades.

Em 1866 a família Carreño se mudou para a Europa e no mesmo ano ela perdeu a mãe. Nesse período, seu pai fundou em Paris uma Academia de Música, sustentando a família com os rendimentos desta. Teresa o ajudava, dando aulas, e compunha, aumentando a receita familiar com a publicação de suas peças.

Residindo na França até 1874, ela conheceu Gioacchino Rossini e Franz Liszt. Tocou em Londres e lá conheceu Arthur Rubinstein, com quem mais tarde teve aulas, e muitas outras personalidades musicais da época. Tocou também na Holanda, na Bélgica e na Escócia, onde inesperadamente se apresentou em uma ópera, substituindo uma cantora. Foi quando começou, como pianista, a abandonar a "música de salão", que vinha privilegiando em seus concertos.

A Companhia com a qual se apresentava como cantora se transferiu para os Estados Unidos, abandonando a Europa, sempre em turbulência e agitação política. E Teresa os acompanhou. Em Nova Iorque se casou pela primeira vez, em 1873, aos vinte anos, com o violinista Emile Sauret, com o qual formava um duo de sucesso. A filha Emilita nasceu em 1874, ano em que morreu seu pai. Ambos continuaram a tocar juntos e tiveram mais uma criança, que perderam com menos de um mês de nascimento. Em 1875 foi abandonada pelo marido e, com o choque, sofreu um aborto. Na mesma época, desalentada e sem recursos, deixou Emilita, adotada por uma senhora alemã, e seguiu para Boston como correpetidora (ou pianista acompanhadora) de uma Academia. Elogiada pela proprietária da escola, recomeçou a cantar. Foi quando conheceu o barítono Giovanni Tagliapietra, com quem se casou em 1876. Com ele teve Lulu em 1878, falecida em 1881; Teresita, em 1882 e Giovanni em 1886.

Em 1883, pelo $1^{\circ}$ Centenário de Nascimento de Simón Bolívar, o governo da Venezuela encomendou-lhe um hino à memória do grande herói, e ela compôs o Himno a Bolívar, que estreou em 1885, em uma apresentação que incluía, entre outras peças, o Concerto em mi menor, de F. Chopin, em que foi solista, e para o qual adaptaram a parte orquestral para um quinteto de cordas. No ano seguinte, o casal fixou residência na Venezuela. 
Enquanto ela, principalmente ela, triunfava (apesar do casal até cantar em dueto), o marido percorria os bares e locais de jogatina, perdendo o que ganhavam. Depois disso, seguidos insucessos os levaram a desfazer a Gran Compañía de Opera Teresa Carreño e regressar aos Estados Unidos. Em Nova Iorque, encontrou o irmão do marido, Arturo, que passou a ajudá-la a cuidar dos filhos e que a defendia nos desentendimentos com Giovanni.

Em 1889 deixou Tagliapietra e voltou com os filhos para a Europa, onde já havia tentado carreira antes, como pianista, passando a morar em Berlim, sede da vanguarda cultural europeia. Foi contratada por Hermann Wolff, o primeiro empresário no sentido moderno da palavra, que passou a cuidar de sua carreira e, apesar de tocar de forma exuberante demais, obteve muito sucesso. Dois anos depois conheceu Eugen D'Albert, também pianista e compositor, onze anos mais novo que ela. Ex-aluno de Liszt, passou todos os seus conhecimentos para a esposa, que o admirava muito. Ela cuidava de um filho dele junto com os seus, de casamentos anteriores, e também das duas filhas, Eugene e Herta, que tiveram juntos. Mas o casamento durou apenas até 1895. Separada, em 1902 se casou com Arturo Tagliapietra, irmão do segundo marido. Permaneceram juntos até a morte dela, em 1917.

\section{Vida familiar}

Ao contrário de Teresa Carreño, Clara teve que lutar para poder se casar, e viveu com Robert de 1840 a 1856 . Foi um período intelectual e musicalmente muito rico, mas do ponto de vista pessoal foi tão sofrido quanto o de Teresa Carreño. Ela não sofreu por abandono, mas sofreu pela presença de um amor muito grande, e muito firme em si, mas ponteado pela oscilação de ânimo e temperamento do marido. Além disso, Robert se sentia rejeitado pelo público, em contraponto com a aceitação sempre unânime dela.

Não há indícios, nos textos biográficos consultados, de que não haja uma razão parecida entre o relacionamento de Teresa Carreño com Emile Sauret, com Giovanni Tagliapietra e com Eugene D’Albert: Sauret e D’Albert eram músicos reconhecidos, mas pode ser (claro, isto é apenas hipótese) que ambos se sentissem diminuídos diante do iniludível carisma da própria esposa. Tagliapietra não era um grande artista, como os outros, e se aproveitava da situação para ser um Don Juan e um jogador, onde quer que estivessem. Robert Schumann sofria ao ser considerado apenas o "marido da pianista", mas seu caráter e seu amor eram maiores que sua vaidade. Clara, desde o início da carreira como concertista, sempre colocou peças dele em seus concertos, e sempre se regozijou quando as obras dele passaram a ser reconhecidas. 
Outro aspecto em que elas se assemelham é o de constantes mudanças de cidade, para moradia, e o enfrentamento de longas e incômodas viagens para suas apresentações. Nesse tempo se viajava principalmente de trem e de navio. Teresa Carreño fez mudanças de continentes, saindo da América do Sul (Venezuela) para a América do Norte (Estados Unidos), desta para a Europa, em busca do reconhecimento e incremento da carreira, sobretudo de pianista. Viajou muito pela Europa, foi reconhecida na França e na Alemanha, e terminou seus dias nos Estados Unidos, acompanhada do quarto marido, Arturo Tagliapietra, irmão do segundo, com quem permaneceu casada durante quinze anos, de 1902 a 1917, quando faleceu.

\section{Vida profissional}

Como compositoras, ambas tiveram sucesso relativo, mas constante. Como intérpretes foram sempre muito aplaudidas, e reconhecidas internacionalmente. Clara Schumann começou a se apresentar como pianista em 1830, com onze anos, e parou de tocar em público em 1891, cinco anos antes de falecer. Exerceu a profissão de pianista, portanto, durante 61 anos - a maior parte de sua vida. Teresa Carreño viveu 64 anos, tocou piano em público desde os nove anos, e só parou de tocar, doente, pouco antes de morrer. Isto é, durante 55 anos ela foi profissional. Evidente que só uma verdadeira paixão pela música move dessa maneira uma criatura; mas, no caso delas, havia um outro fator preponderante: a necessidade de exercer a função de provedoras da casa e dos filhos.

Elas mantiveram apreço e admiração, mesmo quando outros grandes pianistas homens dividiam com elas a preferência do público. Teresa conheceu Gottschalk, que lhe deu aulas, e aprendeu com ele a maneira excessivamente brilhante que o caracterizava; o pianista russo Arthur Rubinstein, que a conheceu ainda bem jovem, lhe deu importantes conselhos sobre interpretação. Mais tarde, com Eugen D’Albert, que era um grande e reconhecido pianista, aprendeu uma maneira mais contida e com menos excesso de brilho.

Assim como D’Albert, Clara Schumann sempre se mostrou dona de uma técnica segura e brilhante, mas sem exageros. Este modo de tocar a levou a ser muito considerada pelos compositores paradigmáticos da fase mais esplendorosa do romantismo: Johannes Brahms, seu amigo desde 1853; Felix Mendelssohn, de quem sempre tocava uma ou mais peças em seus recitais; e, entre muitos outros, o próprio Robert Schumann, com quem viveu uma história de amor já muitas vezes transformada em filme. Além disso, foi seu grande esforço que levou a obra dele a público, e lhe deu a 
grande alegria de ser indagada pelo próprio Berlioz a respeito da música de Robert. Esta, entre muitas outras ações afirmativas, de que ele tanto necessitava.

Ambas contavam também, sempre, com as aulas de piano que ministravam, maneira de complementar a renda familiar, sempre deficitária, com tantas pessoas a sustentar. No caso de Clara, temos o filho Ferdinand, ferido na guerra entre França e Prússia, que morreu aos 42 anos: como mãe, sustentava também a família dele. Outra fonte de renda foram as edições de partituras, já que nessa época havia um grande consumo de música impressa, adquirida por profissionais e amadores, estes, para os saraus tão frequentes em todos os níveis da burguesia.

Para Teresa Carreño, um acontecimento, entretanto, não foi muito feliz: ela doou os direitos autorais de sua valsa Teresita (dedicada à própria filha) ao editor, que havia sido muito amigo e generoso com ela. E aconteceu que esse foi o maior sucesso da casa editora, rendendo muito dinheiro que, se ela não perdeu, pelo menos deixou de ganhar...

A questão do dinheiro sempre permeou a biografia de ambas. Por ocasião do pedido judicial da permissão de casamento entre Clara e Robert, o pai dela escreveu à amiga Emilie List (1818-1902) ameaçando que, se a filha não renunciasse ao casamento, a deserdaria e confiscaria a fortuna pessoal dela!

Já Teresa Carreño enfrentou uma batalha ao separar-se de Eugen D’Albert em 1895, segundo narrativa de Edith Stargard-Wolff, filha do empresário de ambos. Esta amiga conta que D’Albert era muito avaro, e que por ocasião do divórcio queria pagar a mínima pensão a ela e às filhas, o que acarretaria um verdadeiro desastre pecuniário à família.

\section{A mulher na sociedade da época}

Neste breve resumo vemos que estas duas trabalhadoras da música, com todas as diferenças de formação, de temperamento, de biografia, de vida, enfim, foram o suporte - as mantenedoras de suas respectivas famílias: Clara Schumann, que viveu 76 anos, se sustentou e sustentou a família durante mais de 50 anos. Teresa Carreño, que viveu 64 anos, também foi provedora familiar pelo mesmo tempo. Foram sempre excelentes mães, sem deixar de ser excelentes artistas.

No período em que viveram, a vida pessoal, doméstica, particular, era a única opção para as mulheres. A vida pública era muito restrita e em geral suscitava desconfiança quanto a aspectos morais. Não havia espaço para as mulheres no que hoje chamamos "mercado de trabalho". Ambas, Clara e Teresa, conseguiram trabalhar, sobreviver e sustentar seus filhos porque inverteram a função do piano na sociedade, 
num momento em que este representava um elemento valorizador na educação feminina, um "adorno" para a conquista do casamento.

A nobreza da atividade pianística, a riqueza e a distinção do meio em que foram profissionais, disfarçavam o fato de ser uma função remunerada, coisa malvista para mulheres. Talvez por essa razão ambas são sempre mencionadas pelo "talento, criatividade e conhecimento", e poucas vezes há referência às suas atividades musicais como o "exercício de uma profissão".

Raramente se usa a palavra "trabalho", quando se escreve sobre elas e outras musicistas de destaque. Muito menos a palavra "profissão". E, em verdade, tocar qualquer instrumento, ou cantar, exige um preparo diário de horas, mesmo no intervalo temporal entre uma apresentação e outra, que pode ser de meses. Também nos processos de criação, no período em que viveram, há bem mais exigências no conhecimento musical. Na música dita clássica ou erudita (estes rótulos são sinônimos) o conhecimento de regras de Harmonia, Contraponto, Instrumentação, etc., são necessários, o que implica também em tempo de aprendizado.

Clara Schumann e Teresa Carreño criaram obras em gêneros consagrados: Clara, um Concerto para piano op. 7 e um Trio para piano, violino e violoncelo op. 17, além de muitas peças para piano e para canto e piano, sempre no paradigma da música clássica; Teresa, um Quarteto de Cordas e uma Serenata para Cordas, e muitas peças para piano, grande parte "de salão", mas sempre escritas com critério e bom gosto.

Hoje em dia podemos ouvir em gravações as peças de autoria de ambas. E com isso perceber que se enquadram entre os melhores talentos musicais do século XIX.

\section{Bibliografia}

LÉPRONT, Catherine. Clara Schumann. Tradução de Eduardo Brandão. São Paulo: Martins Fontes, 1990.

MARCIANO, Rosario. Teresa Carreño, Compositora y Pedagoga. Monte Avila Editores, s.d.

MONTEIRO DA SILVA, Eliana. Clara Schumann: Compositora $x$ Mulher de Compositor. São Paulo: Ficções Editora, 2011.

PEÑA, Israel. Teresa Carreño (1853-1917). Biblioteca Escolar, "Colección de Biografias", $\mathrm{n}^{\circ}$ 11. Caracas: Ediciones de la Fundación Eugenio Mendoza, 1953. 